\title{
Birth place, practices - a research agenda
}

\begin{abstract}
Background: Risk for mothers, newborns dying are believed to be higher in home than hospital births, but homebirths, research continue.

Objective: Present study was done to know place of birth, mode of delivery, outcome, satisfaction/dissatisfaction amongst tribal women in hilly forestry region with limited resources.

Material Methods: From 52 villages where togetherness with communities was being developed, women, 20 to $35 \mathrm{yrs}$, with at least one birth within 5years were interviewed.

Results: Of 520 births, 229(44\%) had hospital, 291(56\%) home births. Experience was good in $179(78 \%)$, because had known that in case of complications, were at safe place, in safe hands. Fifty women (22\% hospital births) were not happy, 22(12.2\%) said, lost wages, $4.36 \%$ for other reasons, could not explain. Overall 225 had vaginal births, 220 in government, five at private hospitals. Of 223 public hospital births, $38 \%$ were in subdistrict hospital, $60 \%$ at primary health centers $(133$ normal +1 breech), 5 (around $1 \%$ of all) at district, 6 (1\% of all) at private hospital. Of 291 home births, $179(61 \%)$ were conducted by Untrained Traditional Birth Attendants. Of 210 women of 20-25 years, $29(13.8 \%)$ did not get time to go to hospital, 4(1.9) did not have anyone, $20(9.5 \%)$ had transport problem, $115(39 \%)$ felt comfortable delivering at home. Majority 287 of 291(98.6\%) home births, did not have any problem, were satisfied. Of 521 births in 520 women, $87(16.6 \%)$ were obvious preterm. There were $13(2.49 \%)$ SB, $01-(0.19 \%)$ early NND. FGDs revealed women believed TBAs did good job, were competent to deliver even when complications, were scared of operative hospital procedures. Other reasons were difficulties of going to hospital, lost resources, some felt shy. Care for mothers newborns in ways that made sense to women, babies, and health workers is essential.
\end{abstract}

Keywords: births, home, hospital, complications, satisfaction, caesarean section, CSR

\author{
Volume 4 Issue I - 2018
}

\section{Chhabra S}

Director Professor, Obstetrics Gynaecology, Amravati Mahatma Gandhi Institute Of Medical Sciences, India

\begin{abstract}
Correspondence: Chhabra S, Director Professor, Obstetrics Gynaecology, CEO,Aakanksha Shishu Kalyan Kendra, Sewagram, OSD, Melghat Project, Dharni, Utawali, Amravati Mahatma Gandhi Institute Of Medical Sciences, Sevagram - 442102, Wardha, Maharashtra, India,

Email chhabra_s@rediffmail.com,schhabra@mgims.ac.in
\end{abstract}

Received: January 0I, 20I8 | Published: January II, 2018

\section{Background}

Each year, an estimated 5.6million women and babies have been dying due to complications in pregnancy, birth and in the first month of life. This included 303,000 maternal deaths, 2.6million stillbirths and 2.7 million newborn deaths. ${ }^{1}$ The risk for mothers and newborns dying were higher in home births than in the births in hospitals which were fully staffed and adequately equipped from a technical and material perspective. A low risk pregnancy could become high risk rapidly and without warning, requiring a caesarean delivery or other interventions that can safely be performed only in hospital settings. However if the hospitals lacked the needs, such a system would increase the risks may be more than home births because false sense of security is more dangerous than no security.

The debate about the safety of home births continues in the literature, professional policies and practices and so the effects of place of birth and birth outcomes continue to be examined in several studies internationally. On one side the modern day pregnancy, birth cares have created an industry around 'birth processes, a natural physiological process, becoming a technical process. Some of the techniques used are painful or uncomfortable, involving some transgression of bodily or social boundaries. Almost all techniques are performed by people who are essentially strangers to the woman affecting the outcome. On the other side there are many who never see a health professional and deliver at home with their near and dear around and feel satisfied. Buckley ${ }^{2}$ has said that 'anything that disturbs a labouring woman's safety and privacy will disrupt the birth process'. This statement seems the philosophy of essence of home births. Biro et al. ${ }^{3}$ reported that low risk nullipara giving birth at an institution were at significantly increased risk of caesarean section (CS). The impact of place of birth outcomes in a large metropolitan health service in Victoria also revealed negative impact on final outcome of pregnancy including caesarean section rates (CSR).

Encouraging facility-based delivery as a strategy to increase skilled attendance at birth in order to reduce maternal and neonatal deaths, has been a priority in the global maternal health agenda for decades. However women as their right, wanted to be treated with dignity with respect with access to quality care irrespective of their religion, economic status or race. They wanted to give birth in a clean, safe environment with trained health workers who could provide effective care.

\section{Objective}

Present study was done to know the place of birth, mode of delivery, outcome and tribal women's satisfaction/dissatisfaction in a hilly, forestry region with scarce resources and access problems.

\section{Materials \& methods}

After approval of the institute's ethics' committee. Community based ethnographic method was used for the study. Informed consent of the respondents was taken prior to their participation in the research. Study subjects were women from 52villages, (15\% of the villages in Melghat region of Amravati district of Maharashtra province of India) 
within $85 \mathrm{kms}$ from the health facility created for comprehensive, maternal, neonatal care. Togetherness with the communities was being developed. Obviously maternal death cases were not part of the study. However information about morbidity and perinatal loss was collected. In these 52villages, every 10th house was visited, with scope for modification, depending on the number of houses in a village and available women as per the inclusion criteria. Study subjects were married women between 20 to $35 \mathrm{yrs}$, with at least one birth within last 5 years, to reduce memory bias, irrespective whether pregnant or nonpregnant at the time of study, willing to give consent for providing the desired information. Information about the last birth, as per the questionnaire was collected through a predesigned and pretested tool, which had partly closed ended (yes and no answers) and partly open ended questions. Answers were recorded on the questionnaire by the interviewer. Study subjects were not given questionnaire to fill. Focus group discussions were also conducted with the same questionnaire with modification in putting the question as per the need and also age of study subjects and last child birth interval were relaxed in FGDs. All the women willing to join were welcome, $10-15$ at a time.

\section{Results}

Of 520 births, 229(44\%) had hospital births and 291(56\%) home births. Of those women who had delivered in the health facilities (229), the experience was good for 179(78\%), 122 of 20-25yrs, 17 illiterate, 45 with primary school, 42 secondary school, 15 higher secondary education, 2 graduates and one post graduate degree holder. The remaining 57 were of 26-30yrs, 5 illiterate, 10 with primary school education, 32secondary, 8 with higher secondary education, one graduate and one post graduate degree holder. Of all the women who said that their experience was good (179), 74(41\%) said they were satisfied because they had known that in case of complications, they were at safe place, in safe hands and they had safe birth. Fourteen (6.11\%) women said good care of the baby was taken, $20(8.7 \%)$ said they received medication for pain relief during labour and $26(11.35 \%)$ said it was quick management and fast birth. Fourteen (6.11\%) felt good because of clean place and surroundings for the birth. Thirty $(13.10 \%)$ were satisfied because overall good care was taken in the hospital, 33 (14.4\%) said hospital was good, 31(13.5\%) said facilities were good but could not explain anything and $11(4.8 \%)$ were happy because of meals served after birth. However fifty women, $22 \%$ of hospital births said that they were not happy after hospital birth, $28(12.2 \%)$ women were daily wage laborers and family lost wages. So they were not happy about being in the hospital. 12(5.2\%) said that the distance of health facility lead to a lot of inconvenience to everyone in the family. However 10 women $4.36 \%$ of all hospital births, $20 \%$ of all dissatisfied said that proper care was not taken with mistreatment, though they could not explain the details. Of the 229 women who delivered in the hospital, 9(3.9\%) were delivered by specialists, (one CS for transverse lie, 5 normal births at private hospitals), 3 CS at district hospital, (2 referred from Primary health centre (PHC), one for Gestational Hypertension $(\mathrm{GH})$, other in view of multiple pregnancy with GH. Seventy (31\%) women were delivered by medical officers mostly from alternative system of medicine and $150(67 \%)$ by nurse midwives at $\mathrm{PHC}$ or sub centres.

Of 291 home births, 179(61\% of home births) were conducted by Untrained Traditional Birth Attendants (UTBA), because over the years the births in the families were conducted by them, the only ones available and also because the cost was low. Overall 106(36\%) home births were by Trained Traditional Birth Attendant (TTBA), only 5 by nurse midwives and one woman was delivered by her own mother in law because TTBA and NM had gone out of village for some meeting. Of 291 home births, 210 women were of 20-25 years, of which
$29(13.8 \%)$ said they did not get time to go to hospital, 3(1.4\%) felt shy delivering in front of strangers, $35(16.6 \%)$ had no specific reason and said that they did not feel like going to any hospital. 4(1.9) women did not have anyone to take them to the hospital, for $20(9.5 \%)$ transport was not available, $4(1.9 \%)$ did not want to cause any inconvenience to the family at night. However $115(39 \%)$ women did not have any problem. They planned home birth and felt comfortable delivering at home. Out of 74 women of 26-30years, 18 did not get time to go to hospital, $8(10.8 \%)$ were scared to go to the hospital, $45(60.8 \%)$ felt normal and expected everything to be normal so did not go to hospital. 2(2.7\%) delivered at home before they could go to hospital. One woman $(1.3 \%)$ said she did not want any inconvenience to the family at night. Of 7 women of 31-35 years, $5(71.4 \%)$ did not have any problem so stayed at home, one did not have anyone to take her to the hospital and one was scared to go to the hospital. Almost all were satisfied after home births. Majority (287 out of 291(98.6\%)) of women who delivered at home, did not have any problem during birth/ post birth and were satisfied. However $4(1.3 \%)$ did have problems, $2(0.6 \%)$ had heavy bleeding and had to go to private hospital, one was given 2 units of blood transfusion and other one had one unit of blood. In third case woman became unconscious after delivery but was alright after oral fluids, at home. One more had excessive bleeding after delivery, fell down while walking, due to giddiness, got hurt and was given treatment at sub centre for minor injury. She did not need any transfusion.

Overall, of all those who gave birth at the hospitals (229), 225 had vaginal birth, 220 in government hospitals and five at private hospital (of the 6 births at private hospital), 217 normal births, ( 83 at sub district hospital and 134 at primary health centers), 2 had vaginal breech delivery (one at PHC and one at district hospital). There was one twin birth (first twin delivered normally and the second by CS at district hospital). Overall 4(1.7\%) of 229 hospital deliveries had CS (one at private hospital and 3 at district hospital), CSR $0.7 \%$ of total 521 births (Table 1). Overall those who had hospital birth, said they went to hospital because of facilities available, care of the mother and baby and also because of monitory benefits under Janani Suraksha Yojna of Government of India, good food after delivery and also they got atleast 3 days rest. Of all the 223 public hospital births, 84 (38\% public hospital births) were in sub district hospitals, $134(60 \%$ of public hospital births) at primary health center (133 normal +1 breech) \& 5 (around $1 \%$ of all births) at district hospital and $6(1 \%$ of all births) were at private hospital (Table 2).

Out of 521 births in 520 women, 87(16.6\%) were obvious preterm and as per the information, records $449(86.0 \%)$ babies birth weight were $>2.5 \mathrm{~kg}, 72(14.0 \%$ ), low birth weight (LBW), $13(2.49 \%) \mathrm{SB}$, $01-(0.19 \%$ of hospital births $)$ early NND.Overall, these 520 women had 1026 births and lost 13(1.26\%) babies [2 - still births, 6 - infant deaths due to diarrhea, ( 2 at 7 months, 1 at 9months and 3 due to pneumonia at 1yr) and 5 were child deaths due to fever]. Of 291(56\%) home births, $62(12 \%)$ babies had birth weight between 1.5 to $<2.5 \mathrm{~kg}$. $430(82.5 \%)$ weighed between $>2.53 .4 \mathrm{~kg}$. $19(4 \%)$ babies had $3.5 \mathrm{~kg}$ or more birth weight. Those who had home births could get their babies weighed at the Anganwadi within some hrs, after birth or next day. The Anganwadi sewika or Accredited Social health Activist (ASHA) visited the house wherever birth took place. Baby's birth weight was taken at nearby Anganwadi, so there is some bias. FGDs revealed that women believed that TBAs did good job and were competent to deliver even when there were complications. Women were even scared of operative procedures at health facilities and felt shy to deliver with many strangers around. Other reasons were difficulties of going to hospital and resources lost. 
Table I Age, education, socio-economic class parity and place of birth

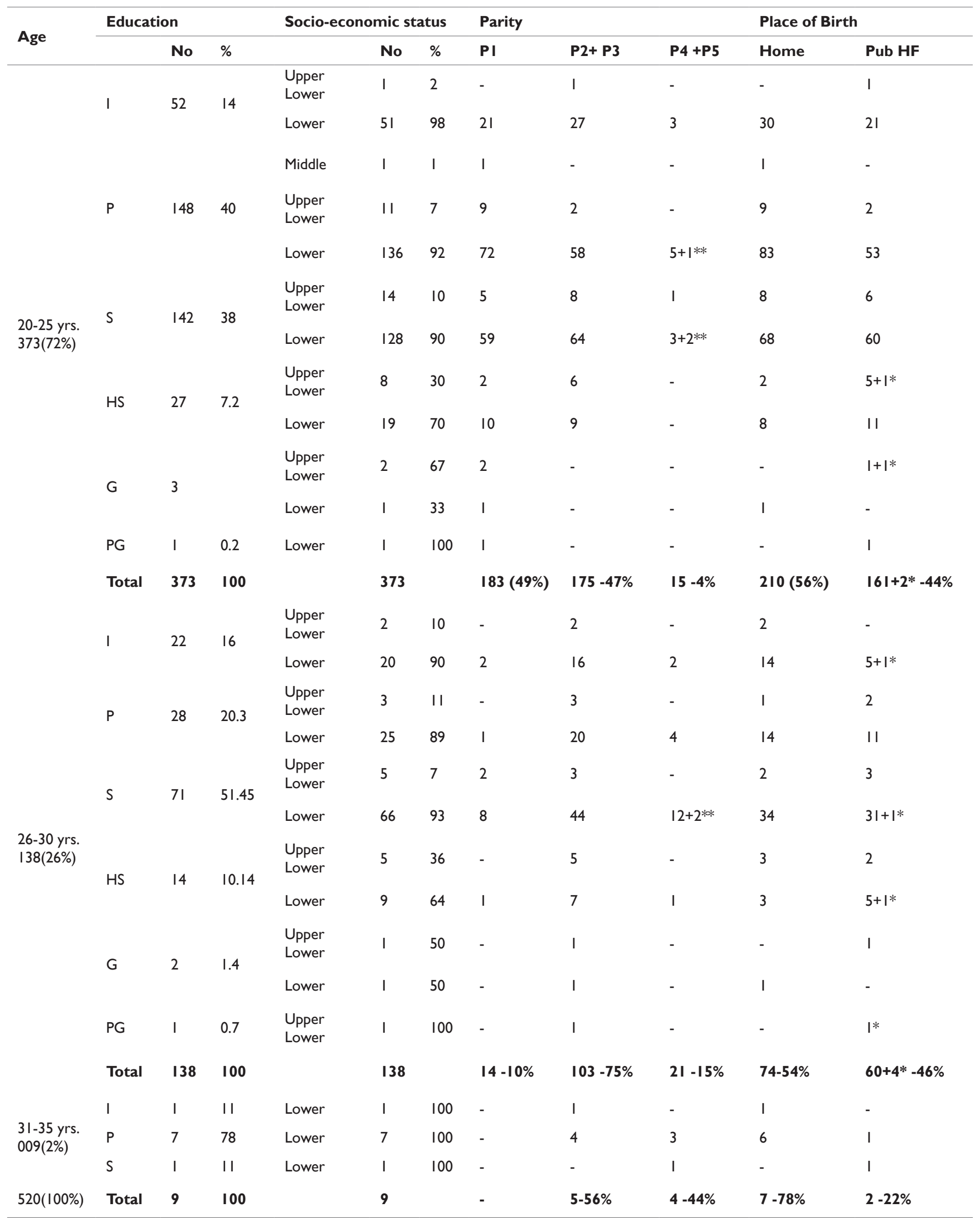

Pvt. HF, Private Health Facility; Pub HF, Public Health Facility; *, Include delivery at Pvt. Hospital; ** Include >P5 
Table 2 Birth Place and Person Conducting Birth

\begin{tabular}{|c|c|c|c|c|c|c|c|c|c|c|c|c|}
\hline \multicolumn{3}{|c|}{ Type of care provider } & \multicolumn{4}{|c|}{ Hospital } & \multirow{3}{*}{ Total } & \multicolumn{3}{|l|}{ Home } & \multirow[b]{2}{*}{$\begin{array}{l}\text { Mother } \\
\text { in law }\end{array}$} & \multirow{2}{*}{ Total } \\
\hline & & & \multicolumn{2}{|l|}{ Pvt. HF } & \multicolumn{2}{|l|}{ Pub HF } & & UTBA & TTBA & Nurse & & \\
\hline & & & Normal & $\mathrm{CS}$ & Vaginal & CS & & & & & & \\
\hline Specialist & & & 5 & I & - & $\begin{array}{l}3 \\
(1-\text { twins*) }\end{array}$ & $\begin{array}{l}9 \\
(4 \%)\end{array}$ & & & & & \\
\hline $\begin{array}{l}\text { Medical } \\
\text { Officer }\end{array}$ & & & - & - & $\begin{array}{l}70 \\
(2 \text { breech } \\
+ \text { I twins } *)\end{array}$ & - & $\begin{array}{l}70 \\
(31 \%)\end{array}$ & & & & & \\
\hline & & Good & 4 & I & 58 & 4 & $\begin{array}{l}67 \\
(29 \%)\end{array}$ & & & & & \\
\hline Experience & & Bad & 1 & - & 12 & I & $\begin{array}{l}13 \\
(6 \%)\end{array}$ & 179 & 106 & 5 & 1 & \\
\hline Nurse & & & - & - & 150 & - & $\begin{array}{l}150 \\
(65 \%)\end{array}$ & & & & & \\
\hline \multirow{2}{*}{ Experience } & Good & & - & - & 112 & - & $\begin{array}{l}\text { I I } 2 \\
(49 \%)\end{array}$ & & & & & \\
\hline & Bad & & - & - & 37 & - & $\begin{array}{l}37 \\
(16 \%)\end{array}$ & & & & & \\
\hline \multirow[b]{2}{*}{ Total } & & & $\begin{array}{l}6 \\
(3 \%)\end{array}$ & & $\begin{array}{l}223 \\
(97 \%)\end{array}$ & & $\begin{array}{l}229 \\
(4 \%)\end{array}$ & $\begin{array}{l}179 \\
(61 \%)\end{array}$ & $\begin{array}{l}106 \\
(36 \%)\end{array}$ & $\begin{array}{l}\mathbf{5} \\
(2 \%)\end{array}$ & $\begin{array}{l}\text { I } \\
(0.3 \%)\end{array}$ & $\begin{array}{l}291 \\
(56 \%)\end{array}$ \\
\hline & $\begin{array}{l}520 \\
(100 \%)\end{array}$ & & & & & & & & & & & \\
\hline
\end{tabular}

UTBA, Untrained Birth Attendant;TBA, Traditional Trained Birth Attendant; Pvt. HF, Private Health Facility; CS, Caesarean Section; Pub HF, Public Health Facility; $\left.*\right|^{\text {st }}$ twin by normal delivery $2^{\text {nd }}$ by caesarean section.

\section{Discussion}

Over all information of 521 births in 520 women revealed quite a lot of useful information about health seeking practices for births by rural women with low resources, quite a lot of positive side, based on which better services, can be built. Literacy was similar in all the age groups. Of 520 cases, $86 \%$ in 20 -25years, $84 \%$ in 26 -30years and $88 \%$ in 31-35 years had some education, however health facility births were more in younger women $44 \%$ in 20 -25years, $46 \%$ in $26-30$ years and $22 \%$ in $31-35$ years (P value 0.357 not significant). CSR was very low, $2 \%$ of 229 hospital births, $0.9 \%$ of all 520 births, with perinatal loss similar to hospital practices and was encouraging. Number of home births was high, almost $60 \%$ but complications rate did not seem to be high. Preterm births were 87 out of births in 520(16.5\%) and number of low birth weight (LBW) babies was not high. Babies of most of the women (449 out of 521) i.e. $86 \%$ had birth weight $2.5 \mathrm{~kg}$ and above, 62 women(12\%) had LBW however gestation at birth may not be exact by what is taken as completed 37 weeks as term as it was gross information specially for homebirths. Also birth weight was taken in some within 6 hrs some others 12 hours and some 24hours with machines where quality check was needed.

Those who delivered at home said that they liked to follow their social customs which was possible at home. They had strong faith on the remedies prepared from forest trees and strong belief that TBAs could conduct deliveries in difficult situations with indigenous remedies and their skills with good maternal and neonatal outcome. Instead of using allopathic medicines, they preferred to use alternative remedies like castor oil. Some even used beverage prepared from Mahua (Madhuca longifolia). Women of these communities had trust on TBAs and preferred to have birth by them rather than going to hospital as they thought TBAs were competent. Also the belief that if anything bad had to happen to the mother or child it would happen, nobody could stop it, not even doctors as it was the destiny of the mother and the child. It appeared that either because of their beliefs or resources, problems of everyday's loss of daily wages, they preferred home births rather than going to any hospital.

A recent article highlighted the pressures women who had desired a natural or vaginal birth in the hospital faced in a culture of medicalized births in the hospitals. The researchers reported that the goal was a call for change to the system of care that steers many women towards c-sections when policymakers and clinician wanted to reduce the CSR. The current system of care did not support women labouring for extended periods, especially those considered high risk, many c-sections were done for "failure to progress' ${ }^{3}$ which seemed misunderstanding of the whole process if labour and births. In many hospitals, $10 \%$ of babies died after caesarean sections, for which dubious indications were main stream, resulting in high maternal morbidity and mortality.5 In 2008, the American College of Obstetricians and Gynecologists reiterated its longstanding opposition to home births, stating that the choice to deliver at home placed the process of giving birth ahead of the goal of having a healthy baby ${ }^{6}$ The Royal College of Obstetricians and Gynaecologists in the United Kingdom issued a statement supporting home births as a viable choice for women with uncomplicated pregnancies. ${ }^{7}$ The Society of Obstetricians and Gynaecologists of Canada recommended research into the safety of all birth settings without specific stand on home birth. ${ }^{8}$

In India, Maharashtra is one of the provinces with better health indicators, but in the Melghat region with tribal population, mortality 
rates of mothers, neonates, infants and children are higher than the state's average. It is hilly region with dense forests known for its tiger reserve, wild life sanctuary but is also known for high maternal, neonatal, infant and child mortality. ${ }^{9}$ In the present study home births were associated with low rates of perinatal complications comparable to hospital births. Study is of live women, so those women who died during the same time were not part of the study. However perinatal loss, maternal morbidity data was available and seemed comparable to hospital births. Despite global, many women are still unable to reach facilities to give birth because of a range of social, geographical, economic and other barriers. Bohren et al. ${ }^{10}$ reported that many women decided not to seek facility based care for birth, despite recognising the associated health benefits because of their previous experiences of poor quality care, including poor treatment, abuse, discrimination and neglect while in facilities. Disrespectful maternity care and mistreatment, occurred in many labour wards around the globe. Continuous and caring support during labour was an evidence based intervention that should be introduced even in labour wards with less privacy. ${ }^{11}$ This could be one reason of home births where there are no strangers, only family members.

Further in the most recent DHS from Nigeria, ${ }^{12}$ there was huge diversity across states. In some states, over $90 \%$ of births were attended by a TBA, in other states; over $90 \%$ of births were attended by an skilled birth attendance ("SBA"). In India, because of the Janani Suraksha Yojana, conditional cash transfer scheme to encourage institutional births, over the past decade, there has been a big increase hospital births, but no corresponding drop in maternal and perinatal mortality because of problem of quality due to various reasons. Risks are high for geographically remote communities and for marginalized groups as was in the present study. Birth companion has been recommended by WHO to improve labour outcomes and women's satisfaction with care. ${ }^{13,14}$ It has also been identified as a key element in the WHO vision of quality of care for pregnant women and newborns. ${ }^{15}$ Several international organizations have expressed support for birth companions as an evidence-based practice that should be scaled-up worldwide, but challenges persist. This is where it becomes evident why tribal people preferred home births as happened in the present study.

Wong et al. ${ }^{16}$ reported that distance from a hospital for rural women showed an even more pronounced effect on utilization. The same was reported in the present study too and was given a reason for dissatisfaction in hospital births. Additionally, researchers have reported the provision of women-centered, respectful maternity care practices in just $4 \%$ of deliveries. ${ }^{17}$ In the study by Raj et al. ${ }^{18}$ mistreatment of women by their providers during childbirth was a pervasive health and human rights violation, and was associated with increased risk for maternal health complications in Uttar Pradesh. While increase in the number of women delivering in health facilities was rapid, the quality of obstetric and neonatal care continued to be poor in India, contributing to high maternal and neonatal mortality. The babies of 'higher risk' women who planned birth in an obstetric unit appeared more likely to be admitted to neonatal care than those whose mothers planned birth at home, but it was unclear if this reflected a real difference in morbidity. Venezuela ${ }^{19}$ formally defined the team "obstetric violence" as the appropriation of women's body and reproductive processes by health personnel, which is expressed by a dehumanizing treatment, an abuse of medicalization and pathologization of natural processes, resulting in a loss of autonomy and ability to decide freely about their body and sexuality, negatively impacting their quality of life..$^{20}$ In Southeast Asia, only $17 \%$ of the poorest women delivered in a facility. Evidence suggested that women were able to judge the quality of health facilities and make decisions about where they will seek care accordingly. In a study only $6.3 \%$ of the studied health facilities had good quality in all three dimensions of quality measures that was done in accordance to the national delivery service guidelines. Systematic and sustained efforts needed to be strengthened to improve all dimensions of quality in order to achieve the desired quality of delivery services and increase the proportion of births occurring in health facilities. ${ }^{21}$

It is important to assess maternal satisfaction with care in order to make it more responsive and culturally acceptable, ultimately leading to enhanced utilization of services and improved outcomes. In the present study many more seemed satisfied after home births compared to hospital birth. At a time when global efforts to reduce maternal mortality have been stepped up, maternal satisfaction needed to be addressed. Women who encounter poor treatment during facilitybased maternity care are less likely to seek health care at a facility in the future. Improving women's experiences with maternal health care will require addressing the root causes. Midwives are best positioned to identify unmet needs, come up with solutions, and implement these solutions. The quality of maternal care was found to be low in Kenya, and care available to the impoverished was significantly worse than that for the better off. To achieve the national targets of maternal and neonatal mortality reduction, policy initiatives need to tackle low quality of care, starting with high-poverty areas. ${ }^{22}$ Solutions must reflect the global standards around the quality of care for mothers and newborns in the ways that made sense to the women, babies and health workers they were meant to support. The majority of women do try to reach health services when an emergency occurs, but all cannot. Present study only few women said they could not go to health facility.

A woman's experience during childbirth has long-lasting consequences for her physical and emotional health and wellbeing. In 2000 , the International Conference on the Humanization of Childbirth was held in Brazil as a response to the trend of medicalized birth and growing concerns over obstetric violence-especially in Latin America. Advocates emphasized the need to adopt a woman-centered approach to maternal health care delivery and ensure that all women are treated with respect and dignity during childbirth in health facilities. ${ }^{23}$

\section{Acknowledgements}

We are grateful to everyone at British Columbia University especially Dr. Shafik, Professor \& Associate Dean, Social Accountability, School of Osteopathic Medicine, University of the incarnate Word. Broadway, Canada, Indo Canadian Shastri Institute, Canada for the support Gratefulness is also due to the women and communities of villages of Melghat region where the study has been done.

\section{Conflict of interest}

Author declares that there is no conflict of interest.

\section{References}

1. Roos N, von Xylander SR. Why do maternal and newborn deaths continue to occur? Best Pract Res Clin Obstet Gynaecol. 2016;36:30-44.

2. https://chriskresser.com/natural-childbirth-i-is-home-birth-more-dangerous-than-hospital-birth/ 
3. Biro PA, Adriaenssens B. Predictability as a Personality Trait: Consistent Differences in Intra individual Behavioural Variation. Am Nat. 2013;182(5):621-329.

4. http://fortune.com/2015/11/04/jamie-dimon-virtual-currency-bitcoin/

5. Rijken M. Hopman P. Illness perceptions of cancer patients: relationships with illness characteristics and coping. Psychooncology. 2015;24(1):11-18.

6. American College of Obstetricians and Gynecologists. ACOG statement on home birth. Washington (DC), USA; 2009.

7. Royal College of Obstetricians and Gynaecologists. Royal College of Midwives Joint statement No.2, April 2007. 2007.

8. http://www.uwo.ca/fammed/csfm/siiren/primaryhealth/rounds_documents/March_2_2011_K_Kilroy_home_birth_facts, biases.pdf

9. Hodin S. Effective Antenatal Interventions to Prevent Maternal and Newborn Mortality. 2016.

10. Bohren MA, Vogel JP, Tunçalp Ö, et al. Mistreatment of women during childbirth in Abuja, Nigeria: a qualitative study on perceptions and experiences of women and healthcare providers. Reprod Health. 2017;14(1):9

11. Roosmalen J, Akkera T. Continuous and caring support right now. BJOG. 2015;123(5):675.

12. https://dhsprogram.com/pubs/pdf/FR293/FR293.pdf

13. WHO. WHO recommendations for augmentation of labour. Geneva: World Health Organization; 2014.
14. WHO. WHO recommendations on health promotion interventions for maternal and newborn health. Geneva: World Health Organization; 2015 .

15. Tuncalp Ö, Were WM, MacLennan C, et al. Quality of care for pregnant women and newborns-the WHO vision. BJOG. 2015;122(8):1045-1049.

16. Wong K, Benova L, Campbell O. A look back on how far to walk: Systematic review and meta-analysis of physical access to skilled care for childbirth in Sub-Saharan Africa. PLoS One. 2017;12(9):e0184432.

17. Hodin S. Quality of routine labor and delivery care in Uttar Pradesh, India. 2017.

18. Raj A, Dey A, Boyce S, et al. Associations between mistreatment by a provider during childbirth and maternal health complications in Utter Pradesh, India. Maternal Child Health Journal. 2017;21(9):1821-1833.

19. VeneZuela S. Birth Abuse. 2007.

20. Hodin S. Respectful Maternity Care: A Basic Human Right. 2017.

21. Fisseha G, Berhane Y, Worku A, et al. Quality of the delivery services in health facilities in Northern Ethiopia. BMC Health Services Research. 2017;17(1):187.

22. Sharma J, Leslie H, Kundu F, et al. Poor Quality for Poor Women? Inequities in the Quality of Antenatal and Delivery Care in Kenya. PLoS One. 2017;12(1): $\mathrm{e} 0171236$

23. https://www.mhtf.org/2017/12/27/from-the-archives-maintaining-the-focus-on-maternal-newborn-and-child-health-with-innovation-and-the-sdgs/?utm_source=MHTF+Subscribers\&utm_campaign=7adcc $5 \mathrm{dbed}$ 